\title{
Distribution of different morphological types of anterior epitympanic plate "cog" and Köerner's septum in CT images of cholesteatomatous and non- cholesteatomatous CSOM: is it really significant?
}

\author{
Lamya Eissa $^{1 *}$ and Walaa Mahmoud ${ }^{2}$
}

\begin{abstract}
Background: The anterior epitympanic plate (cog) and Köerner's septum are gaining more importance since the introduction of transcanal mastoidectomy as these anatomical structures are serving landmarks for the attic. Moreover, different morphological types of cog and Köerner's septum revealed embryological relation to the development of the isthmic membrane; the latter is linked to aeration of the attic and thus affects the pathological development of the cholesteatoma.

Results: A retrospective review of CT images of 86 patients proved by surgical biopsies revealed: 49 cholesteatomas and 37 non-cholesteatomatous CSOM. The type-I "cog" had a higher incidence $(n=40)$ and was statistically more prevalent in non-cholesteatomatous CSOM $(n=30,81.1 \%)$. Type-ll was the second commonest and was statistically more prevalent in cholesteatomatous CSOM ( $n=22,44.9 \%)$. Type-III was the third commonest, seen in $(n=18,20.9 \%)$ and was statistically more prevalent in cholesteatomatous CSOM $(n=17,34.7 \%)$. Köerner's septum was more prevalent in non-cholesteatomatous CSOM (70.3\%) with statistical significance ( $p$ value $=0.002$ ).

Conclusions: The difference in the distribution of different morphological types of anterior epitympanic plate "cog," as well as the difference in Köerner's septum existence amongst cholesteatomatous and non-cholesteatomatous CSOM are suggested as risk factors for the development of cholesteatoma and may predict a cholesteatoma on CT images.
\end{abstract}

Keywords: Cholesteatoma, Mastoiditis, Cog, Isthmic membrane, and Köerner's septum

\section{Background}

Chronic suppurative otitis media CSOM is defined as a persistence of middle ear inflammation for more than 6 weeks and is characterized by discharging ear via a perforated tympanic membrane. Some ears with CSOM

\footnotetext{
* Correspondence: lamya.eissa@gmail.com

'Alexandria Faculty of Medicine, Department of Diagnostic and Interventional Radiology, Alexandria, Egypt

Full list of author information is available at the end of the article
}

develop cholesteatoma with the creation of an enlarging ectopic sac of stratified strongly keratinized squamous epithelium [1-3].

Surgeons and radiologists have made several attempts to classify cholesteatoma [2, 4]. The most widely used classifications are based mainly on either their pathogenesis (congenital or acquired) or on their location in the middle ear cavity in relation to the TM $[1,5]$. Recently, the "European Academy of Otology and Neuro-otology"

\section{Springer Open}

( ) The Author(s). 2020 Open Access This article is licensed under a Creative Commons Attribution 4.0 International License, which permits use, sharing, adaptation, distribution and reproduction in any medium or format, as long as you give appropriate credit to the original author(s) and the source, provide a link to the Creative Commons licence, and indicate if changes were made. The images or other third party material in this article are included in the article's Creative Commons licence, unless indicated otherwise in a credit line to the material. If material is not included in the article's Creative Commons licence and your intended use is not permitted by statutory regulation or exceeds the permitted use, you will need to obtain permission directly from the copyright holder. To view a copy of this licence, visit http://creativecommons.org/licenses/by/4.0/. 
and the "Japanese Otological Society" proposed a new classification system based primarily on extension and complications [4].

Regarding its location, pars flaccida variety is the commonest developing just lateral to the ossicles in the Prüssak's space (subcomponent of epi-tympanum). Pars tensa variety is much less common and often develops in hidden areas such as facial recess or sinus tympani, thus verifying the need for better assessment [5].. Owing to the fact that the epi-tympanum is considered one of the most frequent sites for primary and recurrent cholesteatoma, a sufficient awareness of the surgery-related details about anatomical construction of the epitympanum, the attic, and its adjacent structures is very valuable for the surgeon [6-8].

The anterior epitympanic recess (AER) is a small space in front of the malleus head. A coronally oriented bony septum named the anterior attic bony plate or "Cog" partitionates the anterior epitympanic recess-AER from the epi-tympanum proper (attic) [9]. It is considered the medial continuation of the transverse crest, which is projecting from the tegmen tympani [10]. Moreover, this bony structure and related mucosal fold of this space are closely relevant to the anterior ventilation and drainage of the epi-tympanum and mastoid, which therefore can cause inflammation if got obstructed [11, 12]. The development of chronic otitis media is likely related to morphological types of the "cog" to a certain degree. A completely developed cog is linked to the embryological development of an isthmic membrane, which offers a pathway for aeration via anterior and posterior isthmic. On the other side, incomplete forms of cog are linked to a short or absent isthmic membrane with poor attic ventilation and thus more incidence of cholesteatoma. Thus, the type "cog" carries important pathological concerns. Moreover, the AER is increasingly attaining surgical concerns of its proximity to nearby important structures, where it is serving as a landmark to the attic during cholesteatoma surgery [12].

Another anatomical variant, which may affect the epitympanic aeration is the "Köerner's septum"-(KS), also called the "petro-squamosal lamina." It represents the persistence of the developmental petro-squamous suture line. Köerner's septum is viewed in CT images as a dense bony plate found in the mastoid process. This developmental septum, when present, constitutes a junctional line between superficial squamous and deeper petrous portions of mastoid. It may create problems or complications during mastoidectomy if the surgeon was not informed about its prevalence and morphology [13-15].

Although middle ear (ME) disease can be evaluated with usual otologic and audiometric examinations, more pertinent questions about disease extension and anatomical variants need to be answered. A cholesteatoma in the "hidden areas" like anterior epitympanic recess and sinus tympani can be missed [5]. Surgeons are also blinded with subtle details of anatomical variations of the temporal bone prior to surgery [14-17]. Providing excellent spatial resolution, the high-resolution CT scanning offered an indispensable tool in confirmation of disease extension, identification of anatomical details, and detection of asymptomatic complications [5, 8, 9, $18,19]$. As a matter of fact, HRCT provides a clear roadmap for surgeons to plane the appropriate approach, especially for extensive cases and revision or second look surgery $[20,21]$. This helped by multiple reformations offered in all planes and even double-oblique reformations. The latter technical merit is provided only by multi-slice ( $>16$ slices) scanners, in contrary to oligoslice scanners (16 and less). These multi-slice scanners allow for volume acquisition and reconstruction at only 6 microns slice thickness, with the ability to visualize any structures regardless of its direction due to oblique image reformations [11]. Thus, the cog and KS could be adequately revealed regardless of their orientation.

Mastoidectomy is known to be the classic surgical approaches for the total removal of the disease [14, 15]. The trans-canal endoscopic and microscopic ear surgery approaches offer a new era in the management of limited attic cholesteatoma, providing less invasive surgical technique [21-23]. Still, less invasive surgeries are questioning identification of some landmarks; the "Cog" and "KS," both serving as a guidance route to the attic in both approaches $[24,25]$. The aim of this study is to evaluate a statistical relation between the morphological types of the temporal bone anatomical structures, namely the "cog" and "KS" with an evaluation of their incidence in CSOM with or without cholesteatoma. This was done by a retrospective review of multi-slice CT images for both pathology groups and trying to find a relation between the incidence of a certain "cog" type and existence of "KS" with the development of the type of middle ear disease.

\section{Methods \\ Study description}

The protocol of our retrospective study had approval mad by the Institutional Review Board (IRB) of our university hospital. Patient approval or informed consent was not required for the review of images and clinical records. The study followed a retrospective approach for patients referred to our department by ENT surgeons for chronic ME disease (in the duration between April 2019 and February 2020). The HRCT multiplanar reformatted images of temporal bones in 86 patients were retrospectively reviewed. 


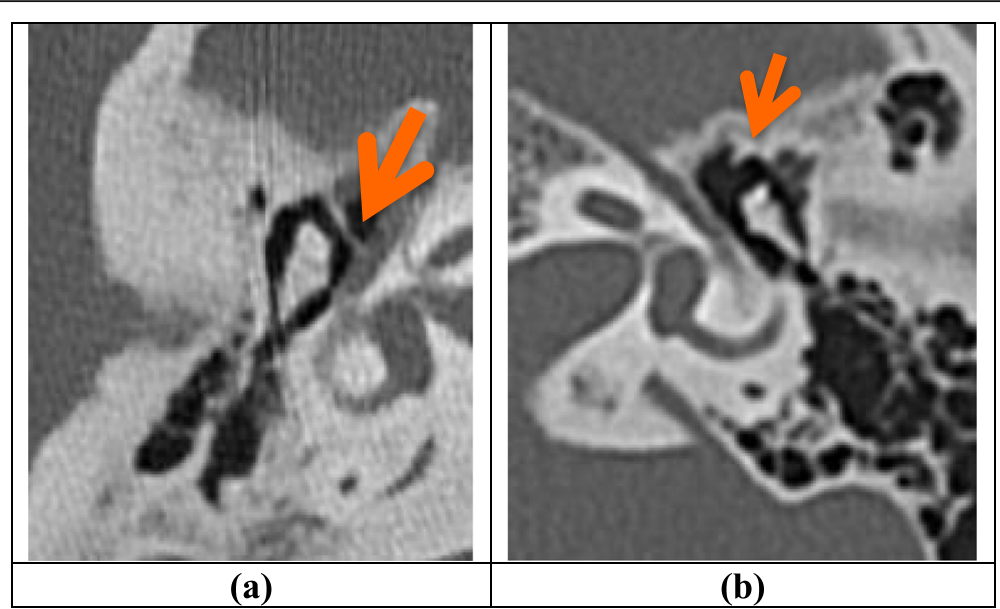

Fig. 1 Cog type-I (a) seen as a thin complete plate as compared to "cog" type-II (b) shown a pyramidal bony projection (colored arrowheads)

\section{Inclusion criteria}

The study was meant to include only (a) adult patients ( $\geq 18$ years old) with (b) proven surgical results of CSOM following mastoidectomies and with (c) unilateral disease.

\section{Exclusion criteria}

The study excluded (a) children ( $<18$ years old), (b) post-operative, and (c) bilateral cases.

\section{CT imaging technique}

All patients were examined using multi-detector row scanner (Somatom sensation-64, Siemens, Germany). Non-contrast and multi-planar images of the temporal bone were acquired in a plane parallel to the orbitomeatal line. The scanning parameters included sectionthickness of $0.5 \mathrm{~mm}$, zero slice interval, pitch of 0.85 , rotation time of $1 \mathrm{~s}$, matrix of $512 \times 512,130 \mathrm{kV}$, and 225 $\mathrm{mA}$. Raw data were reconstructed by using a bone algorithm for optimizing visualization of the bony details of the temporal bone. The reconstructed images were displayed on FOV of $20 \mathrm{~cm}$ at the window level of 450 and window width 4500 of HU. "Double-oblique" reformatted images are made to assess for additional data on the status of the ossicle and bony walls.

\section{Image analysis}

This was done by two radiologists experienced in "Head \& Neck" imaging (with 10 and 15 years of experience). CT examinations were reviewed to identify the morphological variations of anterior attic plate ( $\operatorname{cog})$, and Köerner's septum was reported as present or absent. This is detailed as follows.

\section{Identification of types of anterior epitympanic plate-"Cog"}

The $\operatorname{cog}$ was identified as the posterior boundary of AER in front of malleus head and cochleariformis process. Cogs are classified as types I, II, and III: (a) Type-I: seen as complete thin bony plate crossing at the anterior portion of the attic of the middle ear, dividing the cavity

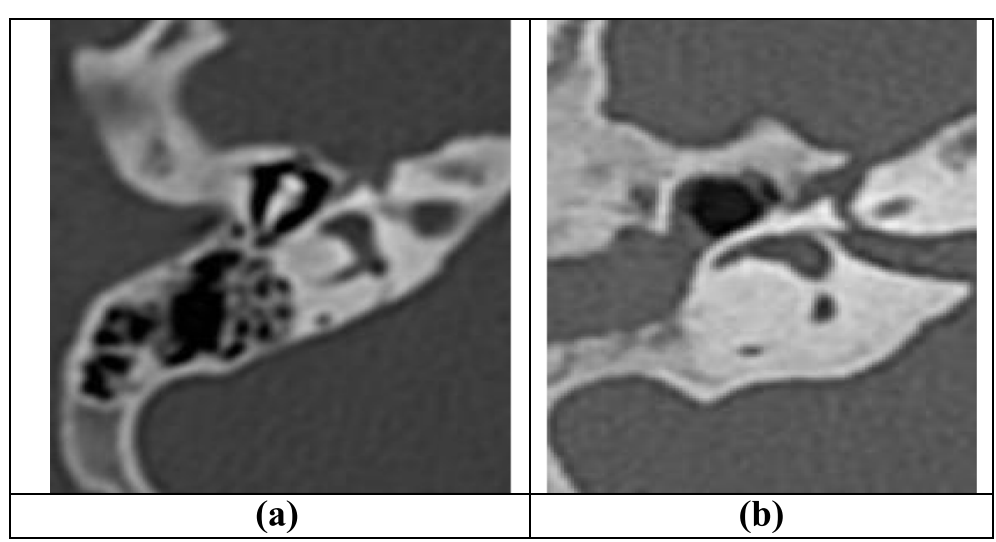

Fig. 2 Type-III-non-visualized: in the absence of opacification (a) and in the presence of opacification (b) 


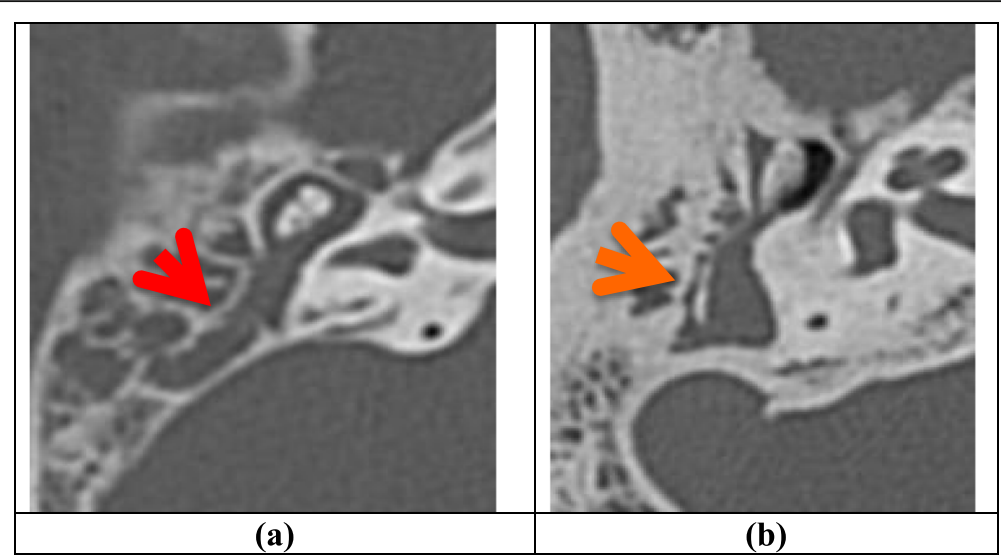

Fig. 3 Köerner's septum (colored arrowheads) is shown as a thin bony plate at the lateral most portion of the mastoid cavity, seen slightly interrupted (a) and complete in (b)

into anterior epi-tympanic recess and attic proper; $(b)$ Type-II: a small bony wedge-shaped bony projection at lateral bony attic wall; and (c) Type-III: non-visualized on CT basis. This pattern of classification was made according to the classification proposed by Lee et al. [21]. The rare event of eroded cog may not be differentiated from this entity, so we preferred to keep the term "non-visualized." The exclusion of bilateral cases was made for this concern. The type of $\operatorname{cog}$ is almost always symmetrical in very individual. So that viewing of the contralateral ear of $\operatorname{cog}$ was part of our imaging viewing, refer to Figs. 1 and 2.

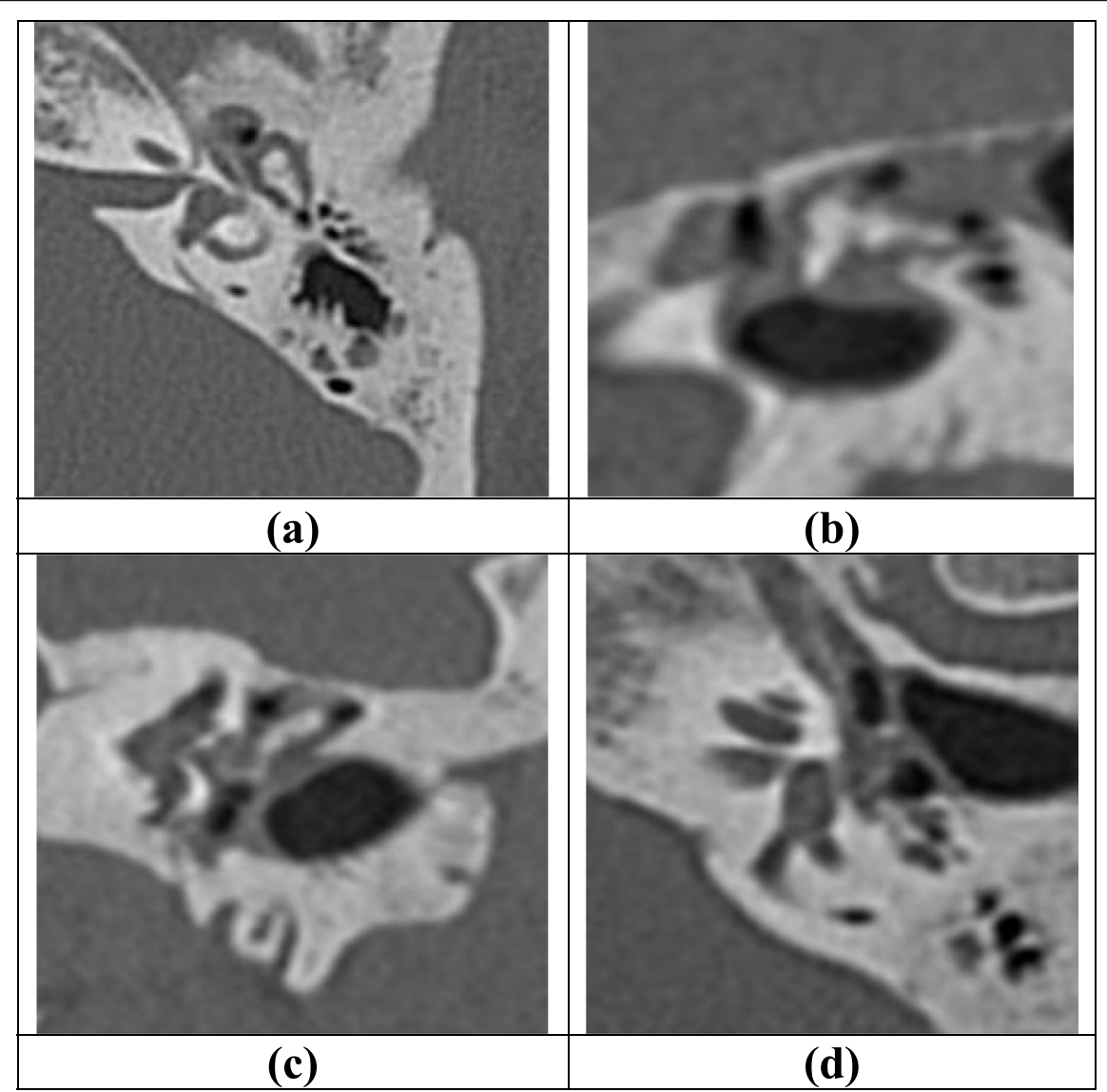

Fig. 4 Case 1: A 32-year-old male with non-cholesteatomatous CSOM, showing type-I cog (a) shown as a complete thin bony plate. Reformatted images in (b), (c), and (d) reveal intact ossicular chain; malleus-incus complex in (b) and (c), and stapedial supra-structure in (d) 


\section{Identification of Köerner's septum (KS)}

KS was identified on the axial image at three points; superior SCC, level of head of the malleus, and level of the sinus tympani. If it is present, it may be complete or incomplete. The Köerner's septum is identified as most lateral near horizontal and near-complete mastoid septum traced anteriorly to the lateral edge of the aditus, and lateral attic wall. The bony line can be seen in different inward and outward curves and with slight interruptions versus smooth continuity, refer to Figs. 3a, b, 4, 5, 6, 7 and 8. No definite classification for KS was made.

\section{Statistical analysis and data interpretation}

Data were fed to the computer and analyzed using IBM SPSS software package version 20.0. (Armonk, NY: IBM Corp). Qualitative data were described using the number and percent. Kolomgrov-Smirnov test was used to verify the normality of the distribution of variables. A comparison between the two groups of patients (cholesteatomatous and non-cholesteatomatous) was made for categorical variables were assessed using chi-square test. Mann-Whitney test was used to compare two groups of abnormally distributed quantitative variables. The significance of the obtained results was judged at the $5 \%$ level.

\section{Results}

The included subjects ranged in their ages from 18 to 86 years old with a mean age of $43.1 \pm 17.4$. Fifty-nine (68.6\%) were males and $27(31.4 \%)$ were females. All patients had a clinical and pathological proof of CSOM either with cholesteatoma in $56.9 \%$ or without in $43 \%$ of temporal bones. The distribution of demographic data according to the type of CSOM is detailed in Tables 1,2 , and 3.

The CT scans of the 49 (57\%) cholesteatomatous CSOM showed variable radiological findings of cholesteatoma: 37 (75.5\%) of them had scalloping of middle ear walls, 33 (67.3\%) of them had widening of aditus, and all of them showed ossicular erosions. The other 37 (43\%) of temporal bones of non-cholesteatomatous CSOM showed less aggressive signs of chronic infection without definite signs of cholesteatoma, apart from three cases with noncholesteatomatous minor erosions. These radiological findings were confirmed post-operatively following mastoidectomies in all cases. The anterior epitympanic recess

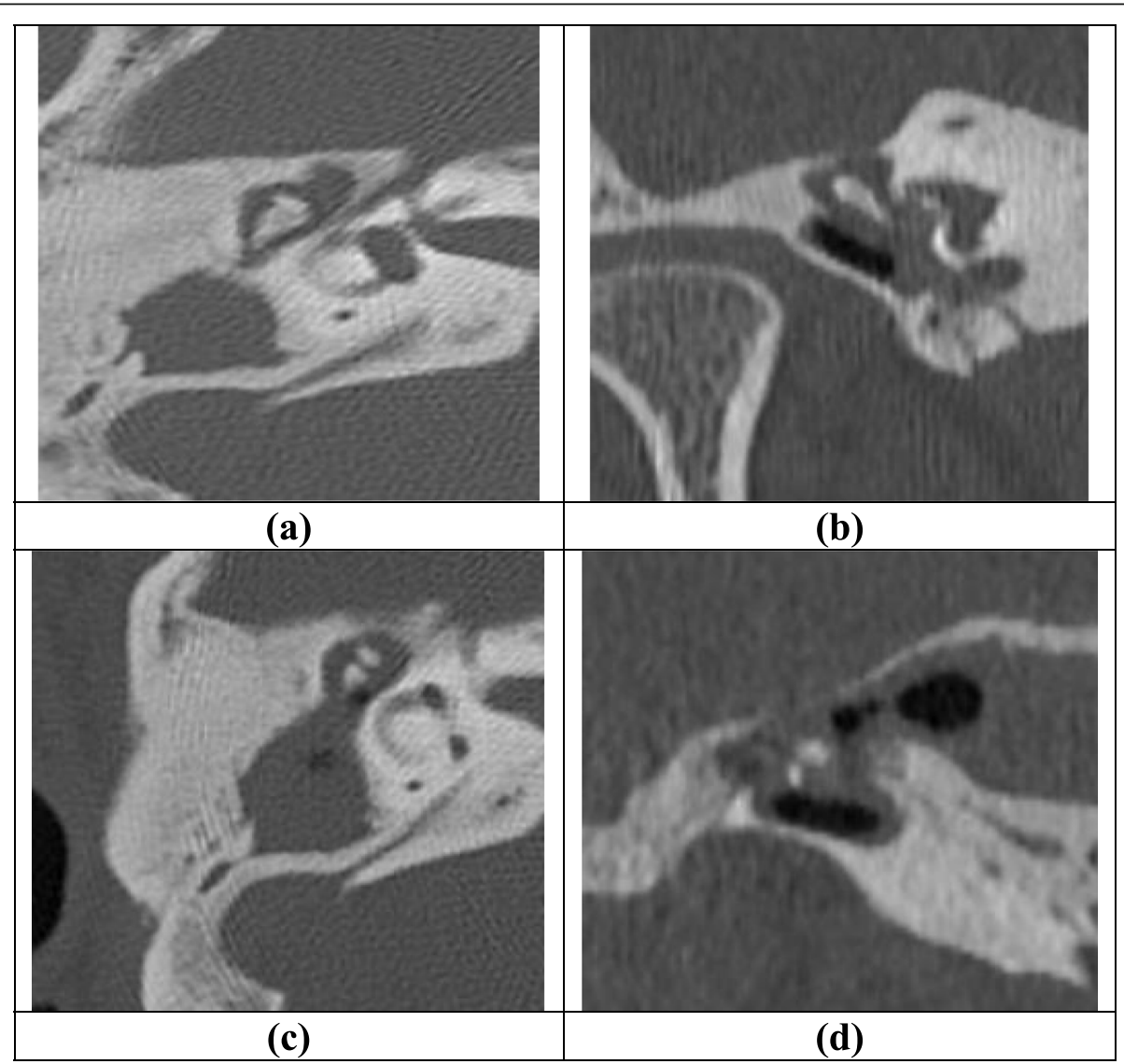

Fig. 5 Case 2 A 25-year-old male presented with proven cholesteatomatous CSOM. a Type-II (pyramidal type) is seen as a pyramidal projection at the lateral margin of the attic. The curved multi-planar image in $\mathbf{b}$ shows erosion of the lenticular process of the incus. Image $\mathbf{c}$ shows the mass effect on the attic and mild aditus widening. Köerner's septum is not visualized. $\mathbf{d}$ Marked tegmental defects 


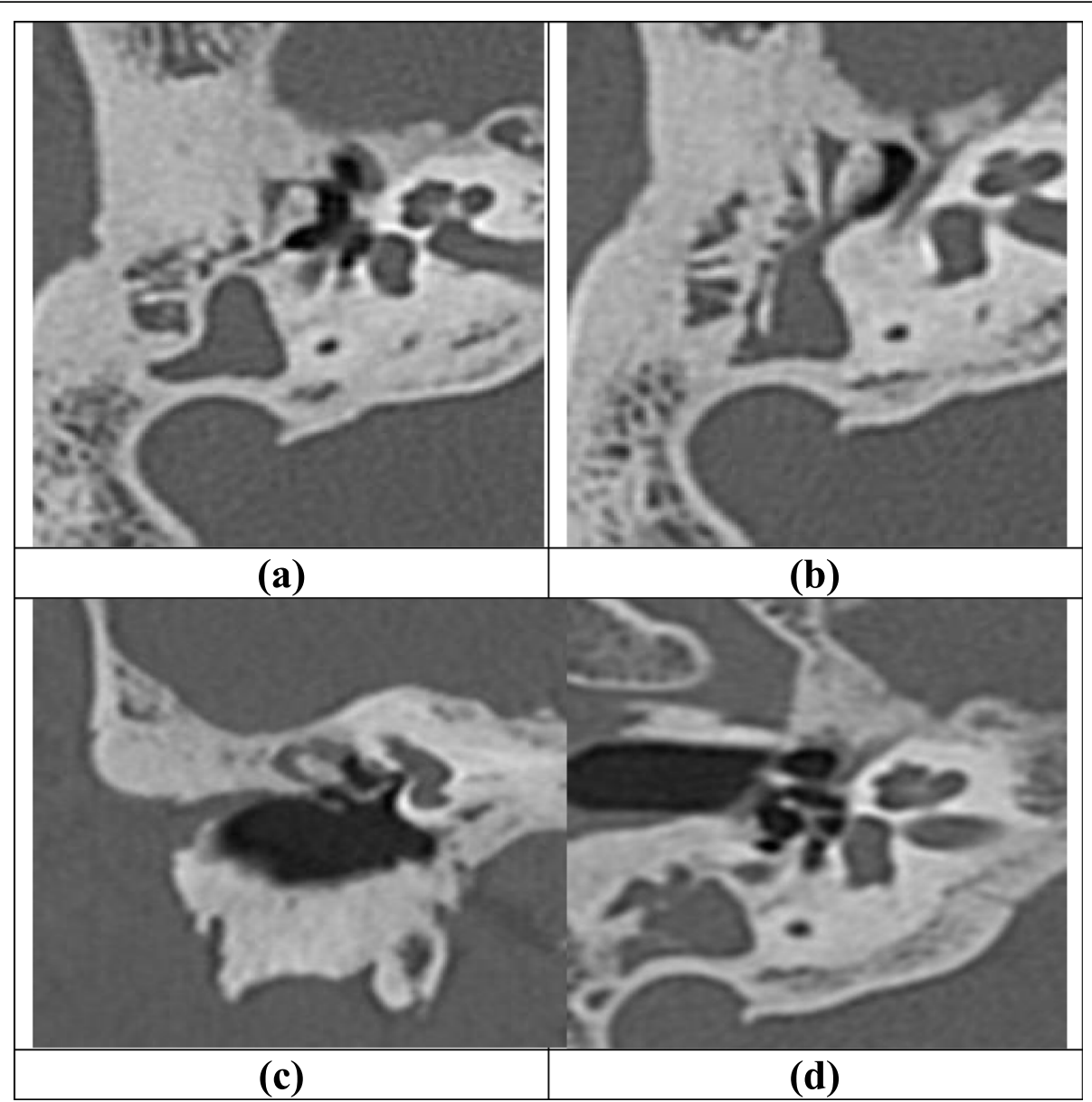

Fig. 6 Case 3: Type-II in non-cholesteatomatous CSOM. Type-II (pyramidal) is seen in $\mathbf{a}$, and Köerner septum is seen in $\mathbf{b}$, at the lateral margin of the opacified mastoid antrum. Curved multiplanar reformats reveal ossicular- $V$ sign of intact incus body and process (This means the $V$-shaped appearance of the intact continuous incudo-stapedial junction is most susceptible to erosions). The stapes is well visualized in $\mathbf{d}$ with intact incudo-stapedial junction

(AER) was involved in $79 \%$ of the diseased ears with no statistical difference between the two groups of patients ( $83 \%$ versus $73 \%$, respectively).

According to its morphology type, anterior attic plate (cog) was classified into three types: (a) Type I (complete plate type) in $46 \%$ of ears ( $20.4 \%$ of cholesteatoma and $81.1 \%$ of non-cholesteatoma with $p$ value $<0.001$ ), (b) Type II (pyramidal-like projection) in $32.6 \%$ of ears (44.9\% of cholesteatoma and $16.2 \%$ of non-cholesteatoma with $p$ value $<0.005$ ), and (c) Type III (non-visualized) in $20.9 \%$ of ears $(34.7 \%$ of cholesteatoma and $2.7 \%$ of noncholesteatoma with $p$ value $<0.001)$. This shows statistical significance in the incidence of mentioned types of "cog" amongst the ME pathology.

Köerner's septum (KS) was not visualized in 15 (17.4\%) of temporal bones (associated coalescent mastoiditis was seen in 4 of them). It was seen as (a) a complete bony septum in 35 (40.7\%) of scanned temporal bones and as (b) an incomplete septum in 8 (9.3\%) of temporal bones. Its prevalence in patients without cholesteatoma (70.3\%) was significantly higher than in those with cholesteatoma $(34.7 \%)$ with ( $p$ value $=0.002)$. In $32.5 \%$, it could not be perfectly evaluated because of extensive sclerosing mastoid bone as a complication of chronic infection.

\section{Discussion}

The anterior epitympanic recess (AER) is frequently involved in chronic infections and represents a common location of the more common pars flaccida growth $[8$, 25]. The complexity of the anatomical architecture of epi-tympanum necessitates accurate and deep knowledge of the surgeon about the spatial relationships present at this site, thus avoiding misguided procedure and inadvertent injury of vital structures [8, 26, 27]. HRCT has a crucial role in the preoperative detailed anatomical information $[9,28]$.

A thin bony plate, cog, protruding down from the tegmen tympani was found reaching antero-superior to the malleus head. The height of this bony plate was 1.5 to 3.0 $\mathrm{mm}$, and when complete, it is seen to extend from the 


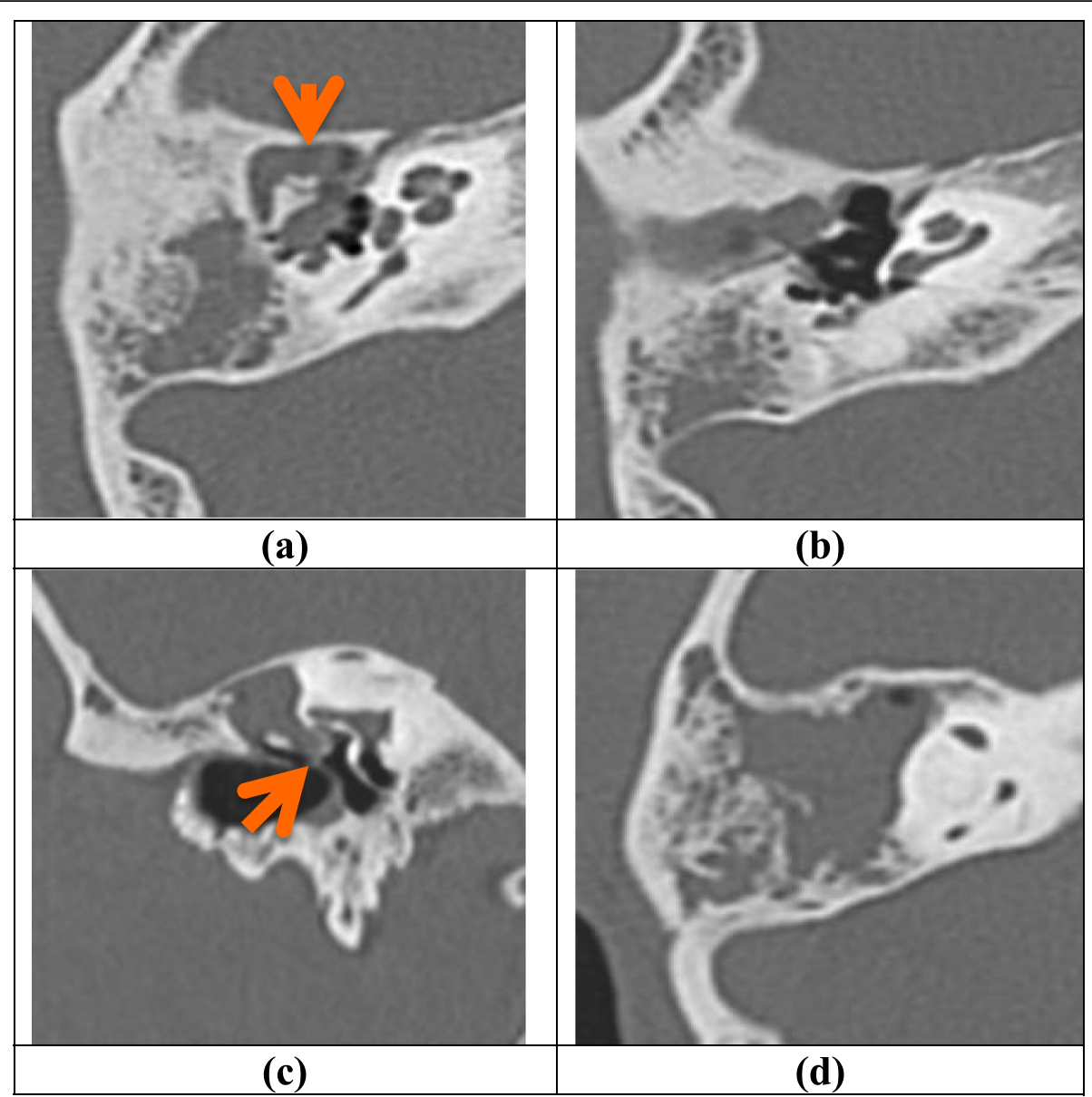

Fig. 7 Case 4: A 22-year-old male: Type-III in cholesteatomatous CSOM. Non-visualized bony projection at any level and this is termed as "Absent." a-c Revealed ossicular erosions of the incus and malleus (arrowheads). $\mathbf{d}$ Revealed marked mass effect with marked attic walls scalloping and marked aditus widening. Also, an element of "coalescent mastoiditis" is seen, so the Köerner's septum cannot be evaluated

facial canal wall to the scutum [29]. The cog is considered a dividing landmark between the anterior and the posterior epitympanic compartments, while the Tensor Tympani mucosal fold (TTF) is subdividing the anterior epitympanic compartment into anterior epitympanic recess (AER) and supra-tubal recess (STR) [10]. Commonly, a vertical type of TTF (mucosal fold) is attached to the cog, and if this TTF is complete, the ventilation to anterior epitympanic recess can be blocked. In that scenario, removal of the $\operatorname{cog}$ and TTF can provide a sufficient ventilation route from the Eustachian tube to the epi-tympanum [10, 30]. Otherwise, in the abovementioned case, the only ventilation pathway will be the "isthmus" which is a narrow pathway between the epitympnum and mesotympanum. This "isthmus" or "isthmic ventilation" is provided through anterior and posterior "isthmi" in an isthmic membrane, the development of which is correlated to the development of the anterior epitympanic plate or so-called Sheehy's cog.
This cog has different morphological variations, which are suggested to carry a good link to the embryological development of the isthmus or isthmic ventilation. A complete thin plate of " $\operatorname{cog}$ " is correlated to a more developed isthmic membrane and thus better isthmic ventilation. On the other hand, more incomplete shallow types of $\operatorname{cog}$ are associated with shorter isthmus and poor ventilation of epitympanum. This shows a good risk for the development of an attic cholesteatoma [31-33].

To best of our knowledge, few studies mentioned two different types of $\operatorname{cog}$ without correlation to chronic infection predisposition [10, 28]. Also, few studies investigated the radio-anatomical assessment of the KS and its predisposition to middle ear infection [13, 14] A single more recent prior study in oto-laryngology literature proposed a classification of morphological types of "cog" on an oligo-slice CT, which was followed in our study on multi-slice CT (MSCT) [12]. The MSCT offers higher 


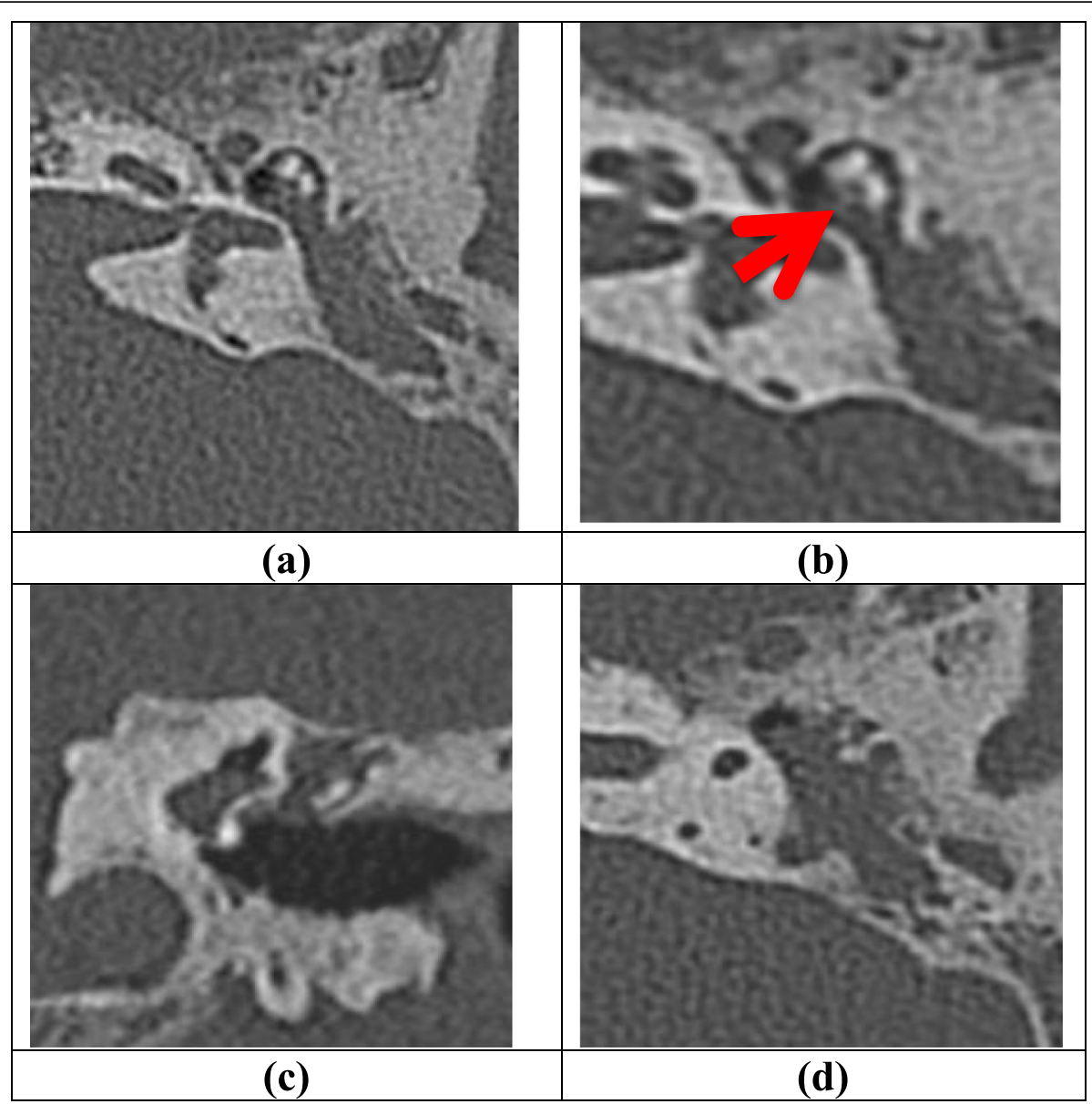

Fig. 8 A 45-year-old male patient. Type-l cog in cholesteatomatous CSOM: Type-l is seen as a complete bony plate. The incus body and process show erosions in $\mathbf{b}$ and $\mathbf{c}$ pointed by an arrowhead in $\mathbf{b}$, matching with post-operative finding of non-cholesteatomatous erosions. The mastoid opacification is seen with failure to identify the Köerner's septum

resolution and multi-planar reconstruction of multi-slice allowing reformations in orthogonal and double-oblique orientation. This is expected to provide higher visibility and better identification of types of anatomical variants under study.
In our study, retrospective CT imaging evaluation of diseased 86 temporal bones revealed 49 cholesteatomas and 37 non-cholesteatomatous CSOM. Three morphological variations of $\operatorname{cog}$ were noticed. It was a complete plate in $46.5 \%$, pyramidal projection in $32.6 \%$, while it was

Table 1 Comparison between the cholesteatoma and non-cholesteatoma according to age and sex

\begin{tabular}{|c|c|c|c|c|c|}
\hline & \multirow{2}{*}{$\begin{array}{l}\text { Total } \\
(n=86)\end{array}$} & \multicolumn{2}{|l|}{ Final diagnosis } & \multirow{2}{*}{$\begin{array}{l}\text { Test of } \\
\text { Sig. }\end{array}$} & \multirow[t]{2}{*}{$p$} \\
\hline & & $\begin{array}{l}\text { Cholesteatoma } \\
(n=49)\end{array}$ & $\begin{array}{l}\text { Non-cholesteatoma } \\
(n=37)\end{array}$ & & \\
\hline \multicolumn{6}{|l|}{ Sex } \\
\hline Male & $59(68.6 \%)$ & $33(67.3 \%)$ & $26(70.3 \%)$ & \multirow[t]{2}{*}{$x^{2}=0.084$} & \multirow[t]{2}{*}{0.772} \\
\hline Female & $27(31.4 \%)$ & $16(32.7 \%)$ & $11(29.7 \%)$ & & \\
\hline \multicolumn{6}{|l|}{ Age (years) } \\
\hline Mean $\pm S D$ & $43.1 \pm 17.4$ & $43.2 \pm 17.8$ & $43.1 \pm 17.1$ & \multirow[t]{2}{*}{$U=902.50$} & \multirow[t]{2}{*}{0.972} \\
\hline Median (Min. - Max.) & $41.5(18-86)$ & $40(18-77)$ & $43(18-86)$ & & \\
\hline
\end{tabular}

$\mathrm{X}^{2}$ : Chi square test, $\mathrm{U}:$ Mann Whitney test

$\mathrm{p}$ : $\mathrm{p}$ value for comparing between Cholesteatoma and Non-cholesteatoma

*: Statistically significant at $p \leq 0.05$ 
Table 2 Comparison between the cholesteatoma and noncholesteatoma according to Cog type (I, II and III)

\begin{tabular}{llll}
\hline Total & Final diagnosis & $x^{2}$ & $p$ \\
\cline { 2 - 3 } & $\begin{array}{l}\text { Cholesteatoma } \\
(n=49)\end{array}$ & $\begin{array}{l}\text { Non-cholesteatoma } \\
(n=37)\end{array}$ \\
\hline
\end{tabular}

\section{Cog type}

$\begin{array}{llllll}\text { I } & 40(46.5 \%) & 10(20.4 \%) & 30(81.1 \%) & 31.194^{*} & <0.001^{*} \\ \text { || } & 28(32.6 \%) & 22(44.9 \%) & 6(16.2 \%) & 7.898^{*} & 0.005^{*} \\ \text { III } & 18(20.9 \%) & 17(34.7 \%) & 1(2.7 \%) & 13.037^{*} & <0.001^{*} \\ & x^{2}(p) & 32.320^{*}\left(<0.001^{*}\right) & & \end{array}$

$x^{2}$ Chi square

$p: p$ value for comparing between Cholesteatoma and Non-cholesteatoma

* Statistically significant at $\mathrm{p} \leq 0.05$

not visualized in $20.9 \%$ of temporal bones. Li et al. [10] had found a cog in all their studied patients with ME disease revealing complete and rudimentary types only. The "complete" type was most commonly seen (89\%). Also, Li et al. [10] pointed to the correlation between types of TTF and abnormal anterior epitympanic recess aeration; however, they found no statistical difference between types of cog and types of TTF [10]. On the other hand, El Anwar et al. [28] and Hong et al [31] made their studies on "nonpathologic" temporal bones. They reported that the cog was a constant boundary of the STR and that the "complete cog" was the commonest among the studied group, which was associated with single-cell STR; seen in (79.5\%) of temporal bones [28, 31].

Lee et al. [12] assumed that the development of the chronic otitis media is relatively correlated to the type of the anterior attic bony plate. They found that in the simply diseased ears, the incidences were $40 \%, 44 \%$, and $16 \%$ for the plate type, pyramid type, and anterior type, respectively, and in the cholesteatoma ear, 30\%, 43\%, and $27 \%$, respectively, with a significant statistical difference. This study mad by Lee et al. [12] included normal and diseased ears. They classified cog into thin and long plate type (67\%), thick pyramid type (28\%), and more anteriorly located type (5\%) in normal ears. Lee et al. [12] reported that $5 \%$ of completely healthy ears showed non-visualized cog owing to its more horizontal orientation making it hard to be visualized by HRCT. Lee et al. [12] explained the relation between cog morphology and ventilation that the plate type was associated with welldeveloped supra-tubal recess and better ventilation of the AER. The "pyramidal type" was associated with shallow or nearly absent supra-tubal recess. The "anterior type" was more frequent in cholesteatoma than in noncholesteatoma with a significant statistical difference owing to association with less ventilation [12].

Our current study adopted the "cog" classification proposed by Lee et al. [12]. In our study, the "pyramid type" was the commonest in patients diagnosed with cholesteatoma (in $45 \%$ ) followed by anterior type (34.7\%), while the plate type was the commonest in patients with non-cholesteatomatous CSOM (in $81.1 \%$ ) with a significant statistical difference. This finding supports the etiopathogenesis of cholesteatoma in a hypo-ventilated recess pre-disposed by incomplete types (II and III), in comparison to good ventilation facilitated by complete "cog" and isthmic membrane.

Recognition of another anatomical variant, "Köerner's septum" before antro-mastoidectomy operations revealed to bear clinico-surgical relevance. During cholesteatoma surgery, a disregarded Köerner's septum may be mistaken as the medial wall of the mastoid antrum resulting under-exposure of operative filed with high possibility for residual cholesteatoma $[13,14,32]$. Moreover, a prominent KS may be confused for the bony lamina covering of the sigmoid sinus with consequent inadvertent entry into antrum or facial nerve injury [13, 33, 34]. Some authors suggested that the middle portion of the Köerner's septum is the cog itself, or an extension of it, and it was regarded as having a role in ventilation of the tympanic cavity [34, 35]. Multiple researches revealed that KS might be disrupted in more than one point along its course [13]. In our study, $17.5 \%$ of temporal bones revealed non-visualized KS with 4 temporal bones showed coalescent mastoiditis. Köerner's

Table 3 Comparison between the cholesteatoma and non-cholesteatoma according to Köerner septum

\begin{tabular}{|c|c|c|c|c|c|}
\hline & \multirow{2}{*}{$\begin{array}{l}\text { Total } \\
(\boldsymbol{n}=86)\end{array}$} & \multicolumn{2}{|l|}{ Final diagnosis } & \multirow[t]{2}{*}{$x^{2}$} & \multirow[t]{2}{*}{$p$} \\
\hline & & $\begin{array}{l}\text { Cholesteatoma } \\
(\boldsymbol{n}=49)\end{array}$ & $\begin{array}{l}\text { Non-cholesteatoma } \\
(\boldsymbol{n}=37)\end{array}$ & & \\
\hline \multicolumn{6}{|l|}{ Köerner septum } \\
\hline Absent & $15(17.4 \%)$ & $12(24.5 \%)$ & $3(8.1 \%)$ & $3.929^{*}$ & $0.047^{*}$ \\
\hline Present & $35(40.7 \%)$ & $13(26.5 \%)$ & $22(59.5 \%)$ & $9.471^{*}$ & $0.002^{*}$ \\
\hline Non-evaluable & 36 (41.9\%) & $24(49 \%)$ & $12(32.4 \%)$ & 2.372 & 0.124 \\
\hline$x^{2}(p)$ & \multicolumn{5}{|c|}{$10.239^{*}\left(0.006^{*}\right)$} \\
\hline
\end{tabular}

$X^{2}$ : Chi square

$\mathrm{p}$ : $\mathrm{p}$ value for comparing between Cholesteatoma and Non-cholesteatoma

*: Statistically significant at $p \leq 0.05$ 
septum was recognized as a complete septum in $40.7 \%$ of our patients and as incomplete septum in $9.3 \%$ of cases [33].

In their study, Przewonzy et al. [34] reported Köerner's septum in 6.5 to $47 \%$ of both healthy and diseased ears, while Wojciechowski et al. [35] reported the prevalence of Köerner's septum as $6.58 \%$ of healthy ears, $30.4 \%$ in ears with retraction pockets, and $17.4 \%$ in simple chronic otitis media without retraction pocket [34, 35]. On the contrary, we found that the prevalence of the KS was $70.3 \%$ in patients with simple chronic otitis media and $34.7 \%$ in those with cholesteatoma, showing a significant statistical difference for being more prevalent in simple inflammation $(p$ value $=0.002)$. A significant number of researches confirmed the impact of Köerner's septum on the predisposition to chronic infection by facilitating blockage of isthmus during inflammation of the middle ear [36-38]. Thus, a prominent Köerner's septum is associated with an increased risk of developing CSOM with or without cholesteatomas.

Preoperative HRCT therefore represents a mandatory guidance to the oto-surgeons. It submits information regarding the spread of disease together with detailed anatomic variations and possible complications to be avoided during surgery. The type of "cog" and Köerner's septum may be written in the radiology report for CSOM cases [39-41]. The main limitation of this study was the absence of a healthy subject group to compare the incidence of $\operatorname{cog}$ and KS between them and diseased groups. It was difficult to differentiate rudimentary from eroded "cog" or "KS" as regard CT appearance. However, the incidence or complete erosions are a quite rare event.

\section{Conclusions}

We concluded that the morphological variations in the anterior attic plate "cog" had a significant correlation to the prevalence of chronic otitis media and cholesteatoma owing to the fact that changes in cog position and morphology can change attic dimensions and aeration. KS was considered as another important anatomical predisposing factor to chronic infection and cholesteatoma. Therefore, the difference in the distribution of different morphological types of anterior epitympanic plate "cog", as well as difference in Köerner's septum amongst cholesteatomatous and non-cholesteatomatous CSOM are suggested as risk factors for the development of cholesteatoma and may predict a cholesteatoma on CT images.

\footnotetext{
Abbreviations

CSOM: Chronic suppurative otitis media; AER: Anterior epitympanic recess; KS: Köerner's septum; HRCT: High-resolution computed tomography; $\mathrm{CT}$ : Computed tomography; TTF: Tensor tympanic mucosal fold; STR: Supratubal recess; TM: Tympanic membrane; ME: Middle ear; MSCT: Multi-slice computed tomography
}

\section{Acknowledgements}

Not applicable.

\section{Authors' contributions}

LE provided the cases and final diagnoses, with detailed description of results. WM gave the idea, wrote the section of the introduction, and provided the whole references for introduction and discussion with making of figure legends. The authors read and approved the final manuscript.

\section{Funding}

This study had no funding from any resource.

\section{Availability of data and materials}

The datasets used and/or analyzed during the current study are available from the corresponding author on reasonable request.

\section{Ethics approval and consent to participate}

All procedures followed were in accordance with the ethical standards of the responsible committee on human experimentation (Institutional Review Board (IRB)" of Alexandria General Hospital on 14th February 2017) and with the Helsinki Declaration of 1964 and later versions. Committee's reference number is unavailable (NOT applicable). No consent was obtained from the patients since it was a retrospective study.

\section{Consent for publication}

This was not needed, as the study is "retrospective."

\section{Competing interests}

The authors declare that they have no competing interests.

\section{Author details}

${ }^{1}$ Alexandria Faculty of Medicine, Department of Diagnostic and Interventional Radiology, Alexandria, Egypt. ${ }^{2}$ Mansoura Faculty of Medicine, Department of Diagnostic Radiology, Alexandria, Egypt.

Received: 28 April 2020 Accepted: 20 August 2020

Published online: 15 September 2020

\section{References}

1. Barath K, Huber AH, Stampfli Z (2011) Neuroradiology of cholesteatomas. Am J Neuroradiol 32:221-229

2. Abdel Razek AA, Ghomim MR, Ashraf B (2015) Computed tomography staging of middle ear cholesteatoma. Pol J Radiol 80:328-333

3. Henninger $B$, Kremser C (2017) Diffusion weighted Imaging for the detection and evaluation of cholesteatoma. World J Radiol 9:217-222

4. Linder TE, Shah S, Martha S (2018) Introducing the CHOLE classification and its comparison to the EAONO/JOS consensus classification for cholesteatoma staging. Otol Neuroradiol 40:63-72

5. Gulati M, Gupta S, Parkash A (2019) HRCT imaging of acquired cholesteatoma: a pictorial review. Insights into Imaging 10:92-99

6. Petrus LV, WM L (1997) The anterior epitympanic recess: CT anatomy and pathology. AJNR 18: 1109-1104

7. Sajjadi H (2017) Endoscopic transcanal modified canal-wall-down mastoidectomy for cholesteatoma. World J Otorhinolaryngol Head Neck Surg 3:153-159

8. Wang $K$, Jiang $Y$, Zhang $Z$ (2018) Extension of the clinical significance of the cog. ORL 80:1-9

9. Marchioni D, Mattioli F, Cobelli M (2009) CT morphological evaluation of the anterior epitympanic recess in patients with attic cholesteatoma. Eur Arch Otorhinolaryngol 266:1183-1189

10. Li B, Doan B, Gruhl R (2017) Endoscopic anatomy of the tensor fold and anterior attic. Otolaryngol Head Neck Surg 158:1-6

11. Lane J, Lindell P, Witte R, DeLone DR, Driscoll C (2006) Middle and inner ear: improved depiction with multiplanar reconstruction of volumetric $C T$ data. Radio Graphics 26:115-124

12. Lee CH, Lee JE, Sang DM (2002) The classification and clinical importance of the anterior attic bony plate on temporal bone CT. Korean J Otolaryngol 45 . 122-126

13. Wojciechoski T, Shadorwa T, Drozd Z (2019) The radio-anatomical assessment of the Korner's septum. Surg Radiol Anat 41:669-673 
14. Karaca CT, Toros SZ, Noseri HK (2012) Analysis of anatomic variations in temporal bone by radiology. Int Adv Otol 8:239-243

15. Costa SS, Rosito LP, Dornelles C (2008) The contralateral ear in chronic otitis media. Arch Otolaryngol Head Neck Surg 134:290-293

16. El-Bahrawy ET, Sorour SS, Badr El-Dine MM (2017) Evaluation of endoscopic surgery for the middle ear cholesteatoma. Zagazig Univ Med J 23:283-300

17. Aslan A, Mutlu C, Çelik O (2004) Surgical implications of anatomical landmarks on the lateral surface of the mastoid bone. Surg Radiol Anat 26:263-267

18. Watts S, Flood LM, Clifford K (2000) A systemic approach to interpretation of computed tomography scans prior to surgery of middle ear cholesteatoma. J Laryngol Otol 114:248-253

19. Abselmonaem G, Almolla R, Ali A (2015) The role of HRCT in evaluation of acquired middle ear cholesteatoma otitis prior surgery. Zagazig Univ Med J 21:449-461

20. Aljehani M, Alhussini R (2019) The correlation between preoperative findings of high resolution computed tomography (HRCT) and the intraoperative findings of chronic otitis media. Clinical Medicine Insights. Ear. Nose Throat 12:1-5

21. Marchioni D, Molteni G, Persutti L (2011) Endoscopic anatomy of the middle ear. Indian J Otolarymgol Head Neck Surg 63:101-113

22. Mas-Estelles F, Fernandez MM, Bisquert BC (2012) Contemporary non-echoplanar diffusion- weighted imaging of middle ear cholesteatomas. Radiographics 32:1197-1213

23. Olszewska E, Wagner M, Bernal-Sprekelsen M (2004) Etiopathogenesis of cholesteatoma. Eur Arch Otorhinolaryngol 261:6-24

24. Rosito LS, Netto LF, Teixeira AR (2016) Classification of cholesteatoma according to growth patterns. JAMA Otolaryngol Head Neck Surg 142:168-172

25. Tarabichi M, Marchioni D, Kapadia M (2016) The epitympanum revisited: endoscopic anatomy. Indian J Otolaryngol Head Neck Surg 68:490-495

26. Maiu A, Catana I, Hrabagiuo O, Petri M, Cosgare M (2013) Anatomical variants of tympanic compartments and their aeration pathways involved in the pathogenesis of middle ear inflammatory disease. Clujul Medical 86(4):352-356

27. Juliano AF (2018) Cross sectional imaging of the ear and temporal bone. Head Neck Pathol 12:302-320

28. El-Anwar MW, Eldib DB, Elmalt A (2019) Supratubal recess and sinus tympani: CT analysis of middle ear hidden areas. Egypt J Radiol Nucl Med 50:49

29. Hoshino T, Suzuki JI (1978) Anterior attic wall anatomy. Arch Otolaryngol 104:588-590

30. Yamasoba T, Harada T, Nomura Y (1990) Observations of the anterior epitympanic recess in the human temporal bone. Arch Otolaryngol Head Neck Surg 116:566-570

31. Hong J, Chen K, Lyu H (2018) Age-related changes in the morphological relationship between the supratubal recess and the Eustachian tube. Auris Nasus Larynx 45:88-95

32. Toros SZ, Karaca CT, Habesoglu TE (2010) Is there a relation between mastoid aeration and Korner's septum? Eur Arch Otorhinolaryngol 267:1523-1526

33. Ozer E, Bayazit YA, Cara C (2004) Korner's septum (petero-squamosal lamina) and chronic ear disease. Surg Radiol Anat 26:118-12

34. Przewonzy T, Kosiniski A, Markiet K (2019) Korner's septum (petro-squamosal lamina): the anatomical variant or clinical problem. Folia Morphol (Warsz) 1:1-7

35. Wojciechowski T, Skadorwa T, Drożdż A, Ciszek B, Szopiński K (2019) The radioanatomical assessment of the Kömer's septum. Surg Radiol Anat 41(6):669-673

36. Puricelli MD, Newby MD, Fishman AJ, Rivera A (2017) The petrosquamous stalactite. Otolaryngol Head Neck Surg 156(3):549-553

37. Deekshith RM, Gangadhara-Somayaji KS (2019) Korner's septum: an uncommon clinical entity. Teaching Imaging 7:134-135

38. Cebeci S, Ozbilen MS, Bayramoglu I (2020) Impact of the demographic and aetiological factors and intraoperative findings on post operative outcome in chronic otitis media surgery. Turkish J Med Sci 50:155-162

39. Abdel Razek A, Haung BY (2012) Lesions of the petrous apex: classification and findings at CT and MR imaging. Radiographics 32:151-173

40. Yu Y, See J, Ng J, Low D, Tan TY, Yuen H (2020) Patterns of middle-ear cholesteatoma and implications for surgical approach. J Laryngol Otol 23:1-5

41. Sun Y, Wang E, Yu J, Zhong G, Zhu L, Wang Y, Xun N, Yu H, Zhou W, Xie Z, Zhang K, Fan G, Zhong Y, Xiao H, Kong W (2020) A novel surgery classification for endoscopic approaches to middle ear cholesteatoma. Curr Med Sci 40:9-17

\section{Publisher's Note}

Springer Nature remains neutral with regard to jurisdictional claims in published maps and institutional affiliations.

\section{Submit your manuscript to a SpringerOpen ${ }^{\circ}$ journal and benefit from:}

- Convenient online submission

- Rigorous peer review

- Open access: articles freely available online

High visibility within the field

- Retaining the copyright to your article

Submit your next manuscript at $\boldsymbol{\nabla}$ springeropen.com 